\title{
Early Intervention to Develop Social Interaction and Communication Skill for Children with Autism Spectrum Disorders
}

\author{
Oom Sitti Homdijah \\ Special Education Department, Faculty of education, Universitas Pendidikan Indonesia, Indonesia \\ Corresponding e-mail: oomshomdijah@upi.edu
}

\begin{abstract}
There is an increasing in the prevalence of children with autism spectrum disorders every year. The major barriers of children with autism spectrum disorder are social interaction, communication and behaviour (triad of impairments). Children with autism spectrum disorders can be identified before the age of 30 months or 36 months. This diagnose can make the stress for some families, because they're different from the typically children and very unique. The impact of stress on the family as a result of the presence of child with autism spectrum disorders can happen to the family both internally and externally. Kathy Labos (2005) states that the internal stress can be divided into stress in the parents; stress in siblings; marital stress; and financial stress. Stress on the parents are guilty feeling and the fear. Guilty feeling has a high contribution to make stress on the family, especially for the parents, and the fear also can be a cause of stress for the parents which is have a high contribution after guilty feeling. This stress will cause an imbalance in the family is no harmony, and make the vulnerability in the family, uncomfortable and unsafe feeling. The family-based interventions are an alternative intervention to develop interaction and communication skills for children with autism spectrum disorders. This is because a conducive family will have a good impact for the development of children with autism spectrum disorders.
\end{abstract}

Keywords: early intervention, children with autism spectrum disorders, social interaction, communication,

\section{INTRODUCTION}

The prevalence of children with Autistic Spectrum Disorders (ASD) is increasing every year. Prior to 2006, the prevalence of children with ASD ratio is 1: 500 , in which each of the birth of 500 babies, one baby which included children with GSA. Research Centre for Disease Control (CDC), United States in 2008, said that the comparison of the GSA in children aged 8 years who are diagnosed with GSA is 1:80. In Indonesia, the prevalence of ASD children is 1: 165 (Kresno Mulyadi, 2010).

WHO (World Health Organization) states that in the last 10 years ASD in Indonesia is rising rapidly, previously was $1: 1000$, now is $8: 1000$, or about 1: 125 (Kompas, 17 November 2011), which means of every baby born in 1000, 8 babies are ASD.

Autistic Spectrum Disorders identified an autism triad of impairments: an impairment of social interaction; an impairment of communication; an impairment of social imagination. Over the past decade a number of related features also associated with autism, these include: sensitivity of sensory, cognitive (type of visual learning; the problem of attention and information processing), are less able to empathize (theory of mind, emotional problems, other problems translating the mood and behavior, joint attention), and this is a characteristic that is not visible (covert) (Dodd, 2005: p. 2-3).

Children with ASD is children who have barriers of communication and social interaction as a result of central nervous system damage, especially the limbic system that existed at the noble function of them. The child with the ASD have an impairment of social interaction which is demonstrated by their inability to respond of stimulus that comes from the people in the surrounding. This inability indicated by: a lack of empathy to others and recognize the role of others in the process of interaction, they can ' $t$ initiate interactions and to respond of other child or adults to interact, they do not have the skills to listen and imitate. 
Bronfenbrenner's ecological systems theory focuses on the quality and context of the child's environment. He states that as a child develops, the interaction within these environments becomes more complex. This complexity can arise as the child's physical and cognitive structures grow and mature (Paquette \& Ryan 2001). The family is nearest environment of a child; therefore, the family has an important role in assisting the development of children.

Early intervention is a role of the parents in supporting the development of children at an early age so that children have optimal development, early intervention is a service development in the natural environment and is intended to meet the developmental needs of children. Because early intervention is done in a natural environment setting then this has a meaning that early intervention is done in an environment that is closest to the child that parents and families

Early interventions or family based intervention to be very important for children with autism spectrum disorders because research shows that between the ages of birth to three years is a period of development that is critical in a child's life, Infants and toddlers who receive early intervention can reduce their need for special services education and more child independent and have a greater opportunity to reach potential optimally.

\section{EARLY INTERVENTION}

Early intervention is the intervention or interference of parents in supporting the development of children at an early age so that children can develop optimally, early intervention is a service developments in the natural environment and is intended to meet the developmental needs of children.

Early intervention carried out of the parents of children who have developmental delays, or children with special needs, including children with autism spectrum disorders (GSA) aims to help the development of children so they can develop optimally., Early intervention services is support in early life children, even early intervention services as early as possible given that starting from birth to school age.

Early intervention is defined as health care, education or therapeutic given under the supervision of the public and designed to meet the developmental needs of infants or toddlers who have developmental delays or disabilities (Eidelman, 2011).

In A Family's Guide to Early Intervention Services in Washington State, said that early intervention is a service developments provided under public scrutiny and in an environment of natural and designed to meet the developmental needs of infants and toddlers who are eligible and to assist parents in supporting development and a child's learning. So basically early intervention designed to help parents understand their children, find ways to help their child's development, providing facilities to help meet their children's development and learning. The purpose of early intervention is to build up the strength of the family by providing coordination, support, resources and services to enhance the development of children who have developmental delays and disabilities through daily living learning.

The intervention is very important in children early age due to several reasons such is that first, scientifically known that early childhood is a time of brain development are significant and substantial growth in each domain development of all children, both that this time, all learning takes place in the context of relationships, and the family is central to this relationship, therefore the family must be involved at every level, then that early intervention is very beneficial for the children of both children in general or for children with special needs (Eidelman , 2011)

That is also the reason for the involvement of parents is very important in early intervention is to provide better opportunities for them in the care of children with special needs, including children with GSA. The purpose of parental involvement in early intervention is to provide emotional support, teaches how parents help their children learn new skills, teach parents how to participate actively in the process of learning programs are individualized, and in the context of the needs of the advocacy of parents (Fallen \& Umansky, 1985: 445).

Research results indicate that parental involvement in early intervention can bring up a child's learning acceleration (Shearer \& Shearer, 1977), which is the power to the constructive changes (Tjosem, 1976). Bronfenbrenner (1974) states that the success of early intervention does not lie to the school, especially the teachers, but on the family, especially the elderly. Family is the key to successful intervention against children both children in general and children with special needs. For children with special needs the family's role is very important in optimizing the development of children, especially the support given by parents to children, and one of the goals of early intervention is to build a positive emotional relationship between child and parent in order to meet the needs of children.

Therefore it is very important to improve motivation, frequency of intercourse and strength in the responses to generate adaptive behavior, which in turn increases the effectiveness of parents in carrying out the functions and role as a teacher (Fallen \& Umansky, 1985). 
Early intervention is important for children with special needs, especially children with autism spectrum disorders. the role of parents and families in the early intervention is very important because most of the time children spend at home with their parents. how parents caring for children with autism spectrum disorders will determine the progress of the child's development. is a family not only parents but their siblings, caregivers or people who are in a family home child with autism spectrum disorders?

\section{AUTISM SPECTRUM DISORDERS}

Autism is the consequence in mental life of a complex disorder of brain development affecting many functions of perceiving, intending, imagining and feeling (Trevarthen, Aitken, Popaudi and Robbarts, 1998).

Wing and Gould (1979 in Dodd, 2005: 2) the first introduced the term triad of impairments, to describe children with autism. The triad of impairments are (1) an impairment of social interaction refers to social relating which means how a person relates and interacts with other people, objects, and events and include skills such as sharing, turn taking and attending to task; (2) an impairment of social communication - this includes all aspects of communication including the comprehension and use of verbal and non-verbal communication to interact and communicate with others. (3) an impairment of social imagination refers to restricted interest and repetitive behaviours are likely to be a product of cognition (thinking), characteristics of autism and are shown as a lack imagination, poor abstract reasoning, limited play skills, concrete thinking and a strong desire for consistency.

Autism is a complex developmental disorder that affects an individual's ability in communication, social interaction and activity of the imagination. Symptoms appear in the before the age of three years.

\section{SOCIAL INTERACTION AND COMMUNICATION}

Social interaction is a reciprocal relationship between individuals, between individuals and group or group by group. Social interaction is a foundation of relationships in the form of an action based on social norms and values that apply and are applied in society.

Norms and rules are very important in social interaction that aims to regulate human life, including social life. According to Prof. Dr. Soerjono Soekamto in introductory sociology, social interaction is the key to all social life.
A person's success in social interaction because it is supported by the social skills he has. Social skill is an overview of an individual's ability to accommodate or adapt to social situations and the ongoing social interaction. (Quill,2000).

Social interaction barriers of children with autism spectrum disorders showed by lack of empathy with other people, lack of awareness of the role others play in the social interaction process, lack of initiation in interaction and response to attempts of other children and adults to interact, limited acceptance of change, limited ability to read the social cues expressed by other people - the looks, body language, gestures, facial expressions and voice intonation. Limited desire to relate to other people.

Communication is a range of purposeful behaviour that is used with intent within the structure of social exchange, to transmit information, observation, or internal states, or to bring about changes in the immediate environment. (Stokes, 1977 in Dodd, 2005).

Communication is a process the sending and receiving the message, and how to share ideas, thinking, and feeling with other. Communication is not only speaking but also need an understanding of what was being said by others and be able interpret the information received to be able to respond.

According to Quill (2000, p. 14) communication is a reciprocal, dynamic process. Communication is a two-way process that requires expressive and receptive communication skills. Expressive communication is an expression of desire, expectations of the individual to the others and receptive communication is how people understand the messages conveyed by others. the sender of the message effectively to convey information in accordance with the purposes and the recipient is actively accept, understand, and interpret the information it receives.

Children with autism have barrier in communication. This showed by lack of pragmatic language; they find it difficult to understand about words that have more than one meaning; saying like 'line up', and 'he's over the hill', abstract(nonconcrete) concepts, sometimes they often fail to alert to human voice; may not respond consistently to own name being called;

Children with autism spectrum disorder have barriers in communication and social interaction. The social interaction barriers shown by no eye contact, poor of facial expressions and body language, less able to wait their turn, no cooperate with others, cannot queue; do not have to share; cannot wait for their turn to play / in social situations. cannot interpret and respond to the actions of others with the right; cannot express thoughts and emotions; do not understand and acknowledge others' viewpoints.; less able to 
appreciate the ownership and cooperate with others in a group situation.

\section{CONCLUSION}

Autism is a consequence of the mental life of the difficulty of complex developmental brain that affects many functions: perceiving, intending, imagining and feeling (Trevarthen et al, 1998). Autistic disorders affect a person's ability in the area: communication, social interaction and restricted interest and repetitive behaviour. These barriers affect the development of children with autistic spectrum, therefore it is important to develop the skills of interaction and communication of children with autism spectrum.

Early intervention is very important to overcome obstacles barriers owned by the child with an autism spectrum disorder because the earlier the intervention the better the child's age to progress the development of children with autism spectrum disorders, particularly in social interaction and communication skills.

The family has an important role in early intervention for children with autism spectrum disorders. the stress experienced by the mother affect family functioning and parenting. Therefore, early intervention to children with autism spectrum disorders are not directly to the child but the most important is the parents' parenting.

Early intervention is very beneficial for the children of both typically development children or for children with special needs, including children with autism spectrum disorders. Early intervention takes place in the context of relationships and family relationships are central to early childhood. That is also the reason for the involvement of parents is very important in early intervention is to provide better opportunities for them in the care of children with special needs, including children with autism spectrum disorders.

\section{REFERENCES}

Cécile Rattaz1, Bernard Ledesert1, Olivier Masson2, Lisa Ouss3, Géraldine Ropers4 and Amaria Baghdadli, Special education and care services for children, adolescents, and adults with autism spectrum disorders in France: Families' opinion and satisfaction, Autism 2014, Vol. 18(2) 185-193 (C) The Author(s) 2012 Reprints and permissions: sagepub.co.uk/journalsPermissions.nav DOI: 10.1177/1362361312460952 aut.sagepub.com. Downloaded from aut.sagepub.com at Universitas Pendidikan Indonesia on March 9, 2016

Cridland, E. K, Jones, S.C, Magee, C.A and Caputi, P. (2014), Family-focused autism spectrum disorder research: A review of the utility of family systems approaches, Autism 2014, Vol. 18(3) 213-222 (c) The Author(s) 2013 Reprints and permissions:

sagepub.co.uk/journalsPermissions.nav DOI:

10.1177/1362361312472261 aut.sagepub.com

Downloaded from aut.sagepub.com at Universitas Pendidikan Indone on March 9, 2016

Dodd, Susan, (2005), Understanding Autism, Australia: Elsevier

Mandelberg, J, Frankel, F, Cunningham, T, Gorospe, C, and Laugeson, E,A, Long-term outcomes of parent-assisted social skills intervention for high-functioning children with autism spectrum disorders, Autism 2014, Vol. 18(3) 255-263 (c) The Author(s) 2013 Reprints and permissions:sagepub.co.uk/journalsPermissions. nav DOI: $10.1177 / 1362361312472403$ aut.sagepub.com. Downloaded from aut.sagepub.com at Universitas Pendidikan Indonesia on March 9, 2016

Michael Siller1,2, Nuri Reyes1,3, Emily Hotez2, Ted Hutman1 and Marian Sigman Longitudinal change in the use of services in autism spectrum disorder: Understanding the role of child characteristics, family demographics, and parent cognitions Autism, 2014, Vol. 18(4) 433-446 (C) The Author(s) 2013 Reprints and permissions:

sagepub.co.uk/journalsPermissions.nav DOI: 10.1177/1362361313476766 aut.sagepub.com. Downloaded from aut.sagepub.com at Universitas Pendidikan Indone on March 9, 2016

Pajareya, K \& Nopmaneejumruslers, K, 2011, A pilot randomized controlled trial of DIR/Floortime ${ }^{\mathrm{TM}}$ parent training intervention for pre-school children with autistic spectrum disorders,autism (C) 2011 SAGE Publications and The National Autistic Society Vol 15(5) 563-577; 386502 1362-3613(2011) Downloaded from aut.sagepub.com at Universitas Pendidikan Indonesia on March 9, 2016

Samadi, S.A \& McConkey, R, \& Kelly, G, Enhancing parental well-being and coping through a family-centred short course for Iranian parents of children with an autism spectrum disorder, Autism 17(1) 27-43 (C) The Author(s) 2012 Reprints and permission: sagepub.co.uk/journals Permissions .nav DOI: 10.1177/1362361311435156 aut.sagepub.com: Downloaded from aut.sagepub.com at Universitas Pendidikan Indonesia on March 9, 2016

Symon J.B.G, Boettcher, M.A, (2008), Family Support and Participation. Effective Practices 
For Children With Autism Educational And Behavioural support Intervention That Work, (19), 455 - 481, New York: Oxford Univercity Press. Ic.

Weiss, J.A, Wingsiong, A, and Lunsky, Y, Defining crisis in families of individuals with autism spectrum disorders Autism 2014, Vol. 18(8) 985-995 (C) The Author(s) 2013 Reprints and permissions:

sagepub.co.uk/journalsPermissions.nav DOI: 10.1177/1362361313508024 aut.sagepub.com. Downloaded from aut.sagepub.com at Universitas Pendidikan Indone on March 9, 2016

Threvarthen, Colwyn, (1999), Children With Autism, Second Edition, Philadelphia: Jessica Kingsley Publisher.

Wetherby, Amy M. dan Prizant, Barry M. (2001), Autism Spectrum Disorder A Transactional Developmental Perspective, Baltimore, Maryland: Paul H. Brookers Publishing Co.

Wing, Lorna, (1974), Autistik Children A Guide for Parents and Professionals, New Jersey: The Chitadel Press

Zager, D, (2005), Autism Spectrum Disorders Identification, Education and Treatment, third edition, London: Lawrence Erlbaum Associates Publishers 